not invariably, stemming from the great Basle Nomina Anatomica of the early years of this century. Any attempt to produce uniformity is, however, fraught with considerable danger, since anatomical terminology enters into many fields of research and classification; and it was felt that great care must be exercised before deciding to inflict any changes on the long-suffering clinicians, who in many cases have already probably had to master at least three different terminologies. It was also agreed, however, that the subject is one of such importance that an approach should be made to the United Nations Educational, Scientific and Cultural Organisation for the purpose of appointing a paid secretary to the committee.

The Congress coincided happily with an exhibition in the Radcliffe Science Library reviewing the history of the teaching of anatomy at Oxford, and a booklet on this subject was presented to each member. The official languages of the Congress were English, French, German, Spanish and Italian, and the interpreters were kept busy. For the most part the delegates were accommodated in Oxford colleges, and during their visit there was no lack of entertainment. Many members took part in sightseeing tours and visits to places of interest; on the last night there was a dance at Oriel College, which was well attended. There was plenty of opportunity for the exchange of informal views and speculations between members who had not seen each other for many years, and the fullest possible use was made of it.

At the closing plenary session, the president referred to the death of Prof. H. C. Bazett, of the University of Pennsylvania, on his way to attend the Congress. It was proposed by Prof. J. Benoit, on behalf of the Association des Anatomistes de Langue Française, that the Sixth International Anatomical Congress should be held under the auspices of the Association, probably in Algiers, in 1955. This invitation was cordially accepted by the members, as was the proposal of Prof. N. L. Hoerr that the American Association of Anatomists should be responsible for the succeeding Congress. The members then dispersed, many of them to pay visits to other laboratories in Great Britain, and all having enjoyed a very pleasant and stimulating few days.

\section{FLUORESCENT INKS FOR ADVERTISEMENT POSTERS}

T

HE use in Great Britain in recent months of unusually brilliant coloured inks on advertisement posters has excited a good deal of interest and comment-some favourable and some otherwise. If, however, it be the purpose of a poster to invite attention, then these inks must be regarded as a success.

The underlying principle of the special inks used for these posters is that they contain a daylight fluorescent pigment which, because it fluoresces in the visible range, imparts the brilliance of colour. The fluorescent pigment is made by dissolving a small quantity of a fluorescent dyestuff in a transparent thermosetting resin (urea formaldehyde or phenol formaldehyde) and grinding the solid solution to a coarse powder. This pigment is then incorporated in a special printing ink containing coloured pigment and oil. Because fine grinding - the usual method of incorporating pigments in oil-destroys the fluorescent properties of the pigment, it is necessary that special inks be used, suitable only for a printing process known as 'silk screen printing'. The usual printing processes used for poster production-lithography and letterpress-demand finely ground inks, and for this reason the fluorescent inks cannot be used. Another reason for using the silk screen process is that it applies a much thicker film of ink to the paper than either lithography or letterpress, and this is an advantage, since the fluorescent inks are not 'permanent'. Even the best of the inks lose their effect after exposure for a month or so. Within limits, however, the thicker the ink film the more permanent is the ink, and hence the desire to print as much ink as possible.

The silk screen process has been used for a number of years for producing posters, showcards, folders, etc., where the number of copies is comparatively few ; but the introduction of the new inks has extended the scale of operation considerably. The process is, in effect, a stencil printing process in which a thin inkmore like a paint than a normal printing ink-is forced through the mesh of $\mathbf{a}$ stencil made from $\mathbf{a}$ piece of silk stretched over a frame (synthetic fibres and wire mesh are also used). The stencil is made either by photographic means or is hand-prepared. The meshes in the image areas are left open, while those of the non-image areas are filled in. $A$ stencil is made for each colour to be printed, and the ink is forced through the silk by means of a squeegee on to the sheet of paper beneath. Although the process can be made semi-automatic, a good deal of hand operation is involved, and hence to produce a large number of impressions is comparatively expensive.

The original patents covering these inks are American, and most of the inks used up to now have been of United States origin. The majority of ink makers in Great Britain, and on the Continent of Europe, are investigating their manufacture. The colours available to date are at the longer end of the spectrum-the reds, yellows and yellow-greens.

\section{CENTRAL GLASS AND CERAMIC RESEARCH INSTITUTE OF INDIA}

$\mathrm{T}$ HE official opening of the Central Glass and Ceramic Research Institute of India at Calcutta by the Honourable Dr. B. C. Roy, Chief Minister, Government of West Bengal, on August 26, brings to fruition a well-planned scheme launched by the Council of Scientific and Industrial Research in India and removes the long-felt and urgent need for the establishment of such an institution in India. This is the fourth laboratory established by the Council to be declared open-the other three being the National Chemical Laboratory at Poona, the National Physical Laboratory at Delhi and the Fuel Research Institute at Dhanbad.

An account of the plans for this latest research institute was given in Nature of March 1, 1947. Although the foundation stone of the Institute was laid on December 24, 1945, by the late Sir Ardeshir Dalal, then member of the Viceroy's Executive Council in charge of the Department of Planning and Development, it was impossible to start work until September 1948. Only the technological block had 